\title{
Stage III Uterine Sarcoma AJCC v7
}

National Cancer Institute

\section{Source}

National Cancer Institute. Stage III Uterine Sarcoma A/CC v7. NCI Thesaurus. Code C8260

Stage III includes: IIIA (T3a, N0, M0); IIIB (T3b, N0, M0); IIIC (T1-T3, N1, M0). T1: Tumor limited to the uterus. T2: Tumor extends beyond the uterus, within the pelvis. T3: Tumor infiltrates abdominal tissues. T3a: Tumor infiltrates abdominal tissues, one side. T3b: Tumor infiltrates abdominal tissues, more than one side. N0: No regional lymph node metastasis. N1: Regional lymph node metastasis. M0: No distant metastasis. This staging applies to leiomyosarcoma, endometrial stromal sarcoma, and adenosarcoma. (AJCC 7th ed.) 